\title{
A Case Series of Percutaneous Treatment of Non-Union Fractures with Autologous, Culture Expanded, Bone Marrow Derived, Mesenchymal Stem Cells and Platelet Lysate
}

\author{
Christopher J Centeno ${ }^{1,3}$, John R Schultz ${ }^{1,3}$, Michelle Cheever ${ }^{3}$, Michael Freeman ${ }^{2}$, Brent Robinson ${ }^{1}$ and Stephen J Faulkner ${ }^{1}$ \\ ${ }^{1}$ The Centeno-Schultz Clinic, Broomfield, Colorado, USA \\ ${ }^{2}$ Department of Public Health \& Preventive Medicine, Oregon Health \& Science University, Portland, Oregon, USA \\ ${ }^{3}$ Regenerative Sciences, LLC; Broomfield, Colorado, USA
}

\begin{abstract}
Background: Current treatment options for stable non-union fractures represent major clinical challenges, and are a major health issue. Fracture treatment can take many forms, usually requiring bone grafting and/or revisions of the fracture with open reduction and internal fixation (ORIF). Conservative care options such as bone morphogenic proteins and bone stimulators are also available. The purpose of this study was to determine if culture expanded, autologous MSC's injected into non-union fractures under c-Arm fluoroscopy could represent an alternative treatment modality in recalcitrant fracture non-unions. This paper reports on the findings of 6 patients with fracture non-union treated with autologous MSC's.
\end{abstract}

Patients and methods: We evaluated 6 consecutive patients with chronic fracture non-unions. Patients consisted of 4 women and 2 men with treatment intervention at an average of 8.75 months post-fracture (range 4- 18 months, one patient fracture not included in calculation was $>100 \mathrm{mo}$.). All treated patients received autologous, culture expanded, mesenchymal stem cells injected percutaneously via fluoroscopic guidance into the site of the fracture non-union. Fracture union was evaluated with the use of follow up high-resolution x-ray and/or CT imaging. Phenotype of the culture-expanded MSCs was evaluated and quantified by flow cytometry of surface antigens.

Conclusion: The results of this study support the hypothesis that autologous MSC's delivered via percutaneous re-implantation may be an alternative modality for the non-operative treatment of recalcitrant non-union fractures.

\section{Introduction}

The economic burden of non-union fractures is significant due to the cost and disability associated with the condition. Of the approximate 5.6 million bone fractures in the United States annually, up to $10 \%$ do not fully heal, and require subsequent treatment [1]. The traditional treatment options for fracture non-union run the spectrum from less invasive bone stimulation techniques using ultrasound and pulsed electromagnetic fields to more invasive interventions including autologous or allogeneic bone grafting either with or without the aid of internal/external fixation. Osteobiologics offer yet another existing approach in treating non-unions $[2,3]$.

Fracture healing is a multidimensional process consisting of four well established remodeling stages; an initial inflammatory response, soft callus formation, initial bony union and bone remodeling. At the cellular level, inflammatory cells, vascular cells, osteochondral progenitors including mesenchymal stem cells (MSC's), and osteoclasts are fundamental in the repair process [4]. MSC's are pluripotent cells found in multiple human adult tissues including bone marrow, synovial tissues, and adipose tissues. Since they are derived from the mesoderm, they have the capacity to differentiate into bone, cartilage, muscle, and adipose tissue [5]. Iwakura et al. [6] demonstrated the hematoma at the initial fracture site contains multi-lineage mesenchymal progenitor cells which are critical in the role in bone healing. Animal and early clinical models have shown that MSC's can be used to regenerate articular cartilage and bone [7-20].

Hernigou has used bone marrow selection to concentrate MSC's and hematopoietic stem cells. This concentrate is then surgically reimplanted into fracture lines to assist in the healing of non-unions [2]. Muschler et al. [21] have also demonstrated a system that relies on selective retention of heterogeneous bone marrow nucleated cells onto a demineralized bone graft. This graft is then re-implanted surgically to promote fusion. A randomized trial of percutaneously injected cultured osteoblasts to treat fractures has been published by Kim et al. [22] showing acceleration in the rate of normal fracture healing. We have previously published on the safety of cultured MSC's for clinical use as well as on selected cases showing orthopedic tissue regeneration [23-25]. However, at the time of the submission of this manuscript, we could find no published work on the use of percutaneously implanted, cultured MSC's as a treatment for fracture non-union. There are obvious advantages to a model that relies on percutaneous injection, as this delivery method would dramatically reduce morbidity over open surgical implant methods.

The purpose of this study is to investigate the feasibility of a less invasive, percutaneous approach for the reimplantation of autologous culture expanded, bone marrow derived MSC's in platelet lysate to enhance fracture repair in recalcitrant stable non-union cases.

*Corresponding author: Christopher J. Centeno, M.D, The Centeno-Schultz Clinic, 403 Summit Blvd., Suite 201, Broomfield, CO 80021, USA, Tel: 303429 6448; Fax: 303429 6373; E-mail: centenooffice@centenoschultzclinic.com

Received October 27, 2011; Accepted December 14, 2011; Published December 16, 2011

Citation: Centeno CJ, Schultz JR, Cheever M, Freeman M, Robinson B, et al. (2011) A Case Series of Percutaneous Treatment of Non-Union Fractures with Autologous, Culture Expanded, Bone Marrow Derived, Mesenchymal Stem Cells and Platelet Lysate. J Bioengineer \& Biomedical Sci S2:007. doi:10.4172/21559538.S2-007

Copyright: (c) 2011 Centeno CJ, et al. This is an open-access article distributed under the terms of the Creative Commons Attribution License, which permits unrestricted use, distribution, and reproduction in any medium, provided the original author and source are credited. 
Citation: Centeno CJ, Schultz JR, Cheever M, Freeman M, Robinson B (2011) A Case Series of Percutaneous Treatment of Non-Union Fractures with Autologous, Culture Expanded, Bone Marrow Derived, Mesenchymal Stem Cells and Platelet Lysate. J Bioengineer \& Biomedical Sci S2:007. doi:10.4172/2155-9538.S2-007

Page 2 of 6

\section{Material and methods}

The research protocol was approved through a non-profit Institutional Review Board (Spinal Injury Foundation-IRB00002637). The definition of fracture non-union differs based on author from 3 consecutive months without radiographic evidence of healing to a minimum of 9 months without union, depending on site and whether infection was involved [26-29]. For the purposes of this investigation, we considered a non-union to be three months without evidence of bridging osteophytes.

\section{Inclusion criteria}

Male or female patients, 18-65 years of age

1. Radiographic evidence of disabling fracture non-union or delayed union with no progression of fracture healing over three consecutive months. Non progression of fracture healing was further defined on radiographs by:

a. absence of bone crossing the fracture site

b. persistent fracture line(s)

c. lack of evidence of progression of healing on serial imaging

\section{Exclusion criteria:}

1. Active inflammatory or connective tissue disease (i.e. lupus, RA)

2. Active non-corrected endocrine disorder potentially associated with symptoms (i.e. hypothyroidism, diabetes)

3. Severe cardiac disease

4. Pulmonary disease requiring medication usage

\section{Pre-procedure data collection:}

Peripheral blood count (CBC) and a multiple serum panel (SMAC) to rule out unknown medical condition (within 3 months of procedure)

\section{Re-implant procedure}

In order to accurately place stem cells into the fracture line, fluoroscopy with injection of radiographic contrast confirming cannulation of the fracture line was utilized. Omnipaque (IohexolGE Healthcare NDC 0407-1413-50) is a non-ionic contrast agent that was used in the present study after first being diluted (1:1 or 1:2) with phosphate buffered saline. We have previously published on the effects of Iohexol on MSC's, demonstrating minimal effects on cell viability [25].

Full informed consent was used prior to the procedure. For one week prior to the marrow harvest procedure the patient was restricted from taking corticosteroids or NSAIDs. Coincident with the marrow harvest procedure, approximately 200cc of heparinized IV venous blood was drawn to be used for platelet lysate (PL). Platelet lysate was prepared via centrifugation at $200 \mathrm{~g}$ to separate platelet rich plasma (PRP) from the red blood cells (RBCs). The PRP was drawn off and stored at $-20^{\circ}$ to produce PL. Platelet lysate was supplemented in cell culture media at $10-20 \% \mathrm{v} / \mathrm{v}$.

For the marrow aspiration procedure, the patient was then placed prone on an operating room (OR) table and the area targeted for MSC harvest (Figure 1) was anesthetized with $1 \%$ Lidocaine, and a sterile disposable trocar was used to draw $10 \mathrm{cc}$ of marrow blood from the right posterior superior iliac spine (PSIS), and $10 \mathrm{cc}$ from the left

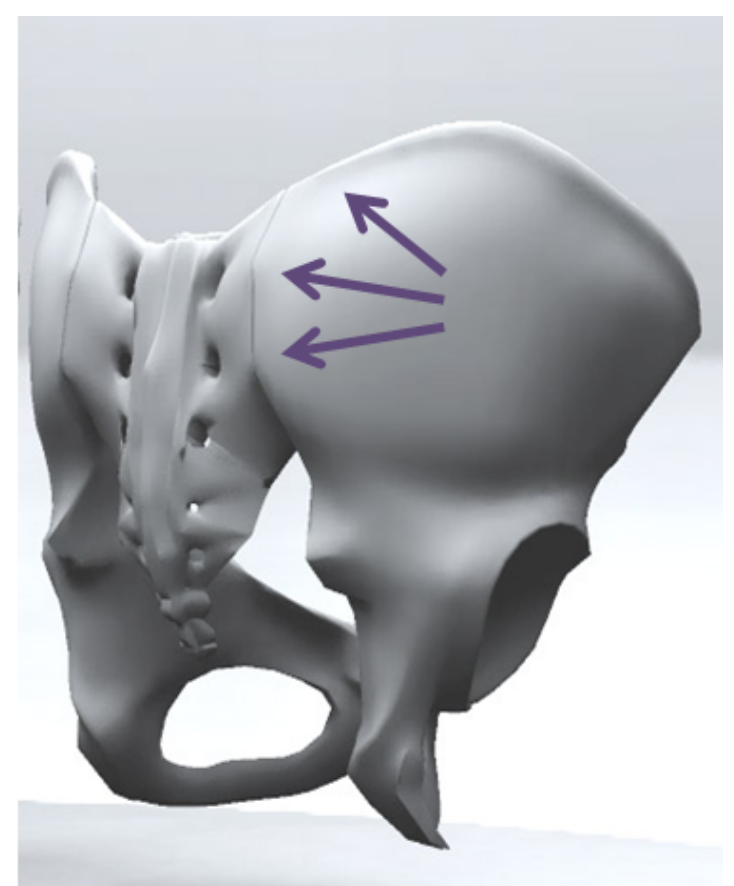

Figure 1: A 3-D model of the human pelvis demonstrating the bone marrow aspirates sites near the PSIS (blue arrows). These sites were confirmed on AP fluoroscopy before the aspiration of marrow.

\begin{tabular}{|l|r|r|r|}
\hline ID & $\begin{array}{r}\text { Stem Cell Yield at } \\
\text { Injection (Millions) }\end{array}$ & $\begin{array}{r}\text { Passage at } \\
\text { Injection }\end{array}$ & $\begin{array}{r}\text { Days in Culture at } \\
\text { Injection }\end{array}$ \\
\hline SB & 29.92 & 5 & 22 \\
\hline JA & 22.32 & 7 & 25 \\
\hline SM & 5 & 5 & 21 \\
\hline MO & 96 & 5 & 24 \\
\hline EW & 3.15 & 2 & 17 \\
\hline BS & 25.1 & 3 & 18 \\
\hline Average & 30.25 & 4.5 & 21.2 \\
\hline St Dev & 34.01 & 1.76 & 3.19 \\
\hline
\end{tabular}

PSIS in syringes containing 1,000 I.U. of Heparin per ml (Abraxis Pharmaceuticals). MSC processing and culture expansion techniques have been described in prior publications [25]. Briefly, nucleated cells were isolated via centrifugation and plated in monolayer culture using autologous platelet lysate. After MSC's had been grown to the 3rd-7th culture passage, they were suspended in phosphate buffered saline (PBS) and platelet lysate. Cell characterization and viability determination was via microscopic morphology grading and intermittent flow cytometry to ensure an MSC phenotype [25].

For MSC re-implantation, the patient was returned to the OR and the area of the non-union site was prepped using betadine and sterile gloves. A sterile trocar (11 gauge x 4-Tyco Healthcare-8881247111) was then inserted using c-arm fluoroscopy as guidance (Seimens Iso-C) into the visible fracture site at several locations. At each site, Omnipaque $(300 \mathrm{mg} / \mathrm{ml})$ contrast was injected and once proper dye flow was demonstrated, cells were injected in a slow and controlled fashion. The trocar was then extracted and the patient was kept in the same position for one hour to allow for cell attachment. Post procedure 


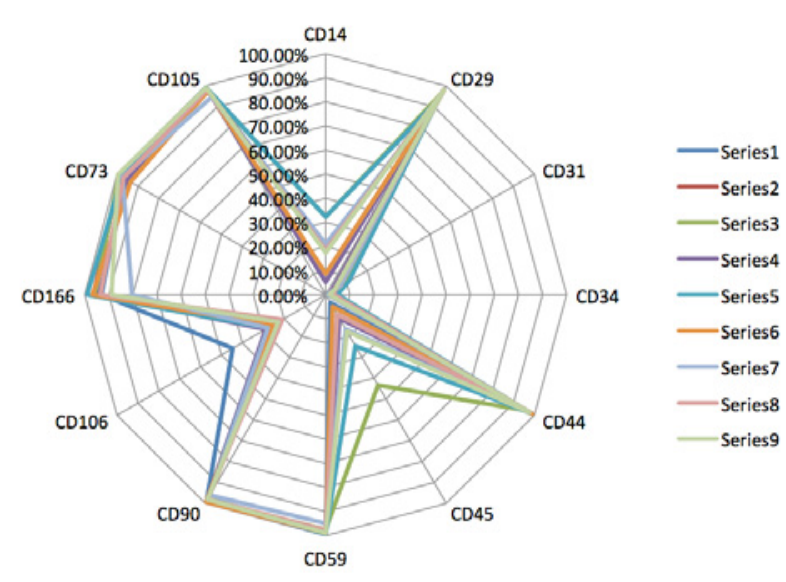

Figure 2: Percentage positive for each cell surface marker using flow cytometry on 9 random MSC samples cultured with this technique.

discharge instructions included returning to activity as tolerated. Post procedure images were obtained at approximately 1 month, 3 months, and if needed at $6+$ months, using matching views (when available).

\section{Results}

Six consecutive fracture patients were actively recruited by an office based, interventional pain practice based on diagnosis and their willingness to proceed with the study. This convenience sample consisted of 6 stable fracture non-unions at various sites. Average time in culture was 21.2 days \pm 3.19 with average MSCs injected at $30.25 \mathrm{X}$ $10^{6} \pm 34.01$. The average passage at injection was the 4 th passage (4.5) with a standard deviation of \pm 1.8 passages ( Table 1 ). Cell morphology in culture was spindle shaped, typical of MSCs in monolayer culture and intermittent flow cytometry of cells grown in culture with this technique demonstrated cell surface antigens consistent with MSC's. (Figure 2).

Of the 6 consecutive patients treated, adequate healing and return to functional recovery was seen in four patients (one patient lost to follow-up-see Table 2). The only fracture that did not heal was the oldest fracture (40 years duration).

\section{Individual Patient Results}

SB was a 37 year old WF with a 9 month old traumatic, nondisplaced, fracture non-union of the distal humerus that had failed ORIF and a bone stimulator trial of 9 months duration (DonJoy CMF OL1000 Bone Growth Stimulator, DJO Inc.; Vista, CA USA). Comorbities included a $1 / 4$ pack per day smoking history with a total of 8 pack-years and morbid obesity. Pre-op radiographs showed no healing (see Figure 3a). Post-treatment radiographs at 5 weeks showed good early healing of the distal humerus fracture (see Figure $3 \mathrm{~b}$ ). The patient returned to full activities by the 2 nd month following implant of MSC's and demonstrated interval healing at 4 months. Final radiograph at 14 months showed excellent healing (Figure 3c).

JA was an 82 year old WF who sustained multiple traumatic pelvic fractures which included acute non-displaced bilateral sacral fractures, right superior pubic ramus fracture and hematoma, and a left anterior acetabular contusion. The patient was known to have severe osteoporosis. Prior to treatment, follow-up thin slice CT at 6 weeks demonstrated no interval healing of the sacral insufficiency fractures at the sacral base and that the fracture lines extended into the

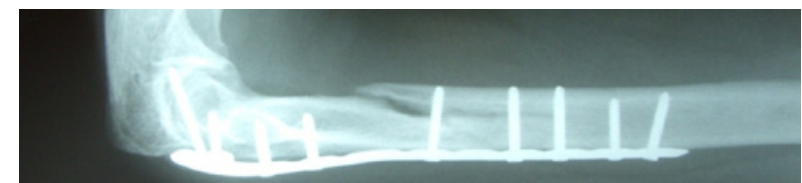

Figure 3a: SB fracture of distal humerus at 9 months post ORIF and after the failure of a bone stimulator.

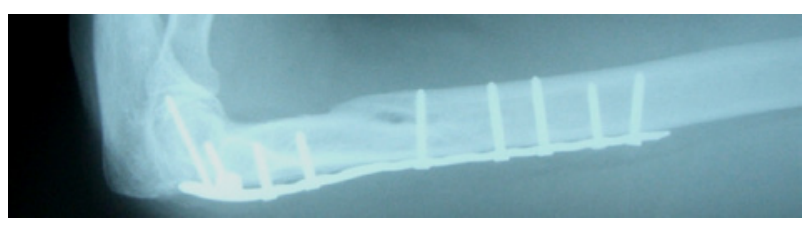

Figure 3b:SB 5 weeks after percutaneous implantation of MSC's.

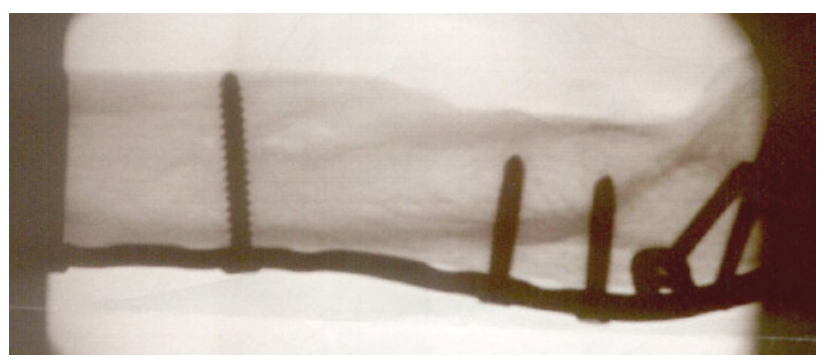

Figure 3c:SB- Healed distal humerus fracture 14 months s/p percutaneous MSC implantation

S2 foramina. As a result, it was deemed that percutaneous injection of polymethylmethacrylate cement might produce neural complications. She was placed into a skilled nursing facility and at 3 months post fracture she was unable to attend physical therapy due to severe pain. The patient was transported and seen in our outpatient clinic where an S2 transforaminal epidural injection of anesthetic and corticosteroids was undertaken for pain control. MSC's were transplanted into the bilateral sacral fracture sites due Tto the patient's primary sacral pain complaints. Eight week post-transplant thin slice CT demonstrated "moderate changes of healing across the superior one-half of both right and left sacral insufficiency fractures" as read by the reading radiologist (site treated). Eight month post-transplant thin slice CT demonstrated "advanced healing across bilateral sacral insufficiency fractures" as read by the same reading radiologist. From a functional perspective, within 4-6 weeks of the transplant, the patient was fully ambulatory with only age appropriate functional limitations.

SM was a 68 year old WF with a long history of multiple sclerosis and significant functional limitation in ambulation related to mild hemiparesis. She presented with an 18 month old fracture non-union of the 1st metatarsal that had failed 18 months of immobilization in a walking boot immobilizer. It should be noted that the patient complained of pain during the percutaneous MSC transplant procedure and as a result, she was unable to tolerate complete insertion of a 22 gauge needle into the faintly visible fracture line (a trocar was deemed too large for this fracture site). Cells were thus deployed outside the fracture line along the periosteum. Follow-up thin slice CT demonstrated moderate healing at 2 and 6 month follow-up with complete return to normal activities by $4-6$ weeks post-transplant. The patient subsequently dropped an object on the same foot at 7 months post-procedure and sustained new injuries, so longer term follow-up was no longer practical. 
Citation: Centeno CJ, Schultz JR, Cheever M, Freeman M, Robinson B (2011) A Case Series of Percutaneous Treatment of Non-Union Fractures with Autologous, Culture Expanded, Bone Marrow Derived, Mesenchymal Stem Cells and Platelet Lysate. J Bioengineer \& Biomedical Sci S2:007. doi:10.4172/2155-9538.S2-007

Page 4 of 6

\begin{tabular}{|c|c|c|c|c|c|c|c|c|c|}
\hline ID & Sex & Age & Co-morbitities & Duration of Non-union (Mo) & Site Treated & Conservative Care & Image Timing (Mo) & Imaging & Result \\
\hline SB & $\mathrm{F}$ & 37 & Smoking, Morbid Obesity & 9 & Humerus & $\begin{array}{l}\text { Immobilization, Bone } \\
\text { Stimulator }\end{array}$ & Pre, $1.2,4,14$ & Radiograph & Complete healing \\
\hline JA & $\mathrm{F}$ & 82 & Severe Osteo-porosis & 4 & Sacral Base & PT, Immobilization & Pre, 2, 8 & Thin Slice CT & $\begin{array}{l}\text { Advanceeeed } \\
\text { healing }\end{array}$ \\
\hline SM & $\mathrm{F}$ & 68 & Multiple Sclerosis & 18 & $\begin{array}{l}\text { 1st meta- } \\
\text { tarsal }\end{array}$ & Immobilization & Pre, 2, 8 & Thin Slice CT & Moderate healing \\
\hline MO & $\mathrm{F}$ & 59 & Chronic Low Back Pain & $>100$ & $\begin{array}{l}\text { Iscial Tuber- } \\
\text { osity }\end{array}$ & None & Pre, $1.5,3$ & Thin Slice CT & $\begin{array}{l}\text { No healing } \\
\text { detected }\end{array}$ \\
\hline EW & M & 67 & $\begin{array}{l}\text { Type II DM, CAD, } \\
\text { Chronic Low Back Pain }\end{array}$ & 4 & Tibia & None & Pre, 2,5 & Radiograph & $\begin{array}{l}\text { Advanced heal- } \\
\text { ing }\end{array}$ \\
\hline BS & M & 25 & Peroneal nerve injury & 24 & Tibia-Fibula & PT, Immobilization & Pre, lost to f/u & Radiograph & Unknown \\
\hline
\end{tabular}

Table 2: Summary of patient demographics and treatment results.

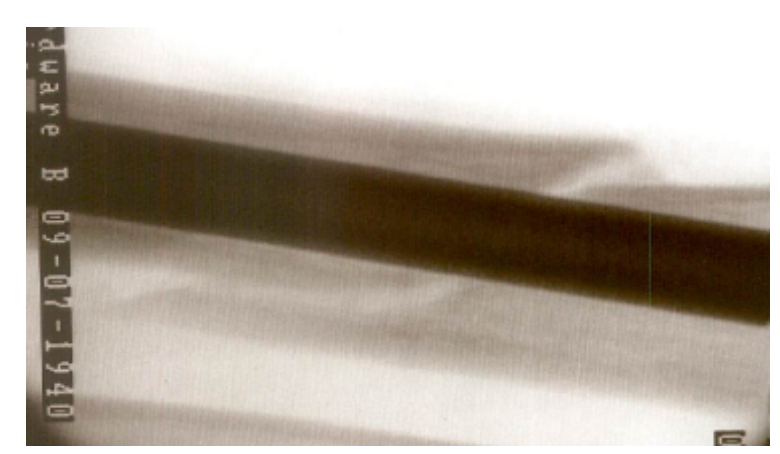

Figure 4a:EW non-healing fracture of tibia and fibula at 4 months s/p ORIF.

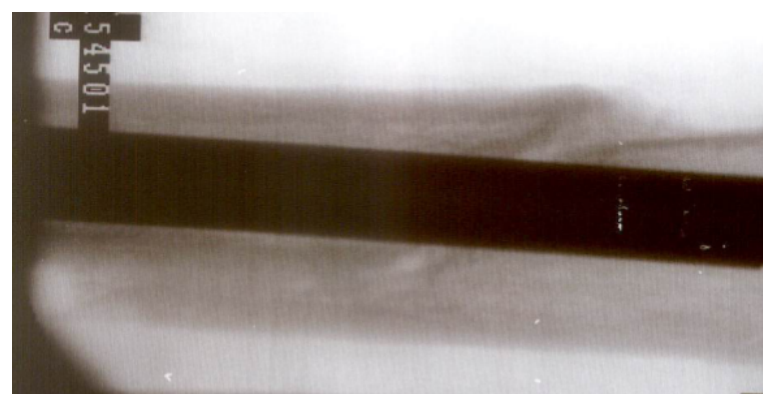

Figure 4b: EW at 5 months after percutaneous implantation of MSC's.

MO was 59 year old WF with a 40 year history of traumatic ischial tuberosity avulsion fracture and proximal hamstring tear. She had a long history of chronic low back pain managed with medications and epidural steroid injections. Two attempts were made at treating the fracture site since she complained of chronic pain localized to the ischial tuberosity which was responsive to local anesthetic injection. Post-treatment thin slice CT scans after both treatments failed to yield any signs of healing as read by the reading radiologist.

EW was a 67 year old WM s/p ORIF with a 4 month old traumatic, tibia-fibia non-union (figure 4a). The patient had difficulty with ambulation. Co-morbities included chronic low back pain with highrisk opioid pain management, type II diabetes mellitus, and coronary artery disease. An MSC transplant was undertaken for the tibia and fibular fractures. While MSC's could be easily placed into the tibial fracture line, the patient reported unacceptable levels of peroneal distribution pain with attempted cannulation of the fibular fracture, so that transplant site was aborted without MSC transplantation. The patient reported return to full ambulation with significant improvements in pain and function at 4-6 weeks post-transplant.
Figure $4 \mathrm{~b}$ shows good healing of the tibial fracture site at 5 months post-transplant. More frequent interval images on this patient proved difficult as his work frequently prevented him from maintaining follow up.

BS is a 25 year old male status post traumatic tibia-fibula fracture with intramedulary rodding without complete healing at two years' post rodding. The patient had not returned to full activities and pain was $5 / 10$. Comorbidities included a likely peroneal nerve injury at that site, detected on initial exam, but not confirmed on EMG/NCS. The tibia fracture was treated by MSC re-implantation into the site. The patient was lost to follow-up, despite multiple attempts to contact him for follow-up data and radiographs.

\section{Discussion}

Four of the six areas treated with percutaneously implanted MSC's showed significant healing on radiographs and good return to full pre-fracture functional activities. The only fracture that showed no signs of healing was a fracture of 40 years duration that was difficult to immobilize (all other patients had immobilization with ORIF or didn't require immobilization due to the nature of the fracture). It is unknown if this treatment failure was due to fracture duration, the nature of the fracture (avulsion fracture), the likely atrophic nature of the local bone healing environment, or the lack of immobilization. Bone reacts to its strain environment to provide signals for cellular healing mechanisms [30]. It is certainly possible that the strain environment of this well adapted, old fracture could no longer produce signals for cellular repair.

JA presented an interesting treatment dilemma. Unlike some senile fractures due to osteoporosis, our analysis demonstrated that stabilizing her non-healing sacral base fracture with injection of PMMA cement would be risky, as communication of the fracture line into the S2 foramen could have led to inadvertent nerve root compression. It should also be noted that JA's outcome was surprising, given that she demonstrated severe osteoporosis both on radiographs and the tactile feel of the trocar at time of treatment. Arguments in the published literature on whether osteoporosis would be expected to negatively impact an MSC procedure can be made on both sides. For example, while MSC's are clearly involved in the differentiation pathway that leads to osteoblasts and bone formation, they have been shown to be less osteogenic with advancing age in females [31-34]. On the other hand, animal models have demonstrated that thickening of bone trabeculae can be induced even with senile MSC's [35].

It is important to clarify that the patients treated all presented with stable non-union fractures, meaning that excessive movement at the fracture line was absent. This inclusion criteria was used as one could postulate that unstable fractures would be less effective than stable non-union fractures without additional fixation and compression. 
Citation: Centeno CJ, Schultz JR, Cheever M, Freeman M, Robinson B (2011) A Case Series of Percutaneous Treatment of Non-Union Fractures with Autologous, Culture Expanded, Bone Marrow Derived, Mesenchymal Stem Cells and Platelet Lysate. J Bioengineer \& Biomedical Sci S2:007. doi:10.4172/2155-9538.S2-007

Page 5 of 6

It is also interesting to note that no biologic scaffolds were used in any of these treatments. While biologic scaffolding combined with MSC's and used for bone repair has become popular in the pre-clinical literature, these results would argue that they may not be necessary in some cases of non-union [16]. In fact, the use of a trocar or needle to cannulate the fracture site may well provide enough trauma to create a whole marrow scaffold. In this study, the placement of cells was accomplished via the use of a 22 gauge needle, which provides a less invasive approach than using a trocar, as described by Hernigou. In addition, Hernigou injected concentrated bone marrow mononucleated cells whereas in this current study, culture expanded MSC's were used, this allows for a ready supply of purified stem cells that can be frozen for future use (i.e. a second application without a second harvest procedure). Finally, Koga has demonstrated that osteochondral repair may be initiated via direct application of MSC's on the osteochondral defect without the use of scaffolding [36].

Many types of percutaneous therapy have been discussed to treat delayed unions and non-unions. However, many of these have significant side effects. For example, BMP's have been shown to lead to nerve root irritation, ectopic bone formation, and antibody formation $[37,38]$. To the contrary, MSC's have been shown to be neuroprotective to the dorsal root ganglia and other peripheral nerves in animal studies [39-42] In addition, the use of PMMA cement has also been shown to result in bone formation in unwanted non-target tissues [43]. No ectopic bone formation was seen in this small case series and no complications were observed.

Platelet rich plasma (PRP) is defined as a concentrate of platelets re-suspended in plasma. PRP has been shown to assist fracture healing [44-46]. While not used here, autologous platelet lysate (PRP that has been lysed via freezing) was used in addition to MSC's. We obviously cannot rule out that platelet derived growth factors may have also played a role in the observed effects here.

\section{Conclusions}

We report these results as preliminarily encouraging rather than conclusive. While this is a small case series, the fact that a combination of expanded bone marrow derived MSC's and platelet derived growth factors can be delivered via trocar or needle to a fracture site may provide some advantages for the therapy of delayed and stable nonunion fractures. In particular, such an approach is significantly less invasive than many surgical options including the placement of autologous bone grafts. While significant positive radiographic changes and concomitant increases in function were seen here in 4 of the 6 patients treated, larger, controlled studies need to be performed to further investigate the treatment approach.

\section{References}

1. Einhorn TA (1995) Enhancement of fracture-healing. J Bone Joint Surg Am 77: 940-956.

2. Hernigou P, Mathieu G, Poignard A, Manicom O, Beaujean F, et al. (2006) Percutaneous autologous bone-marrow grafting for nonunions. Surgical technique. J Bone Joint Surg Am 2: 322-327.

3. Jager M, Hernigou P, Zilkens C, Herten M, Li X, et al. (2010) Cell therapy in bone healing disorders. Orthop Rev (Pavia) 2: e20.

4. Schindeler A, McDonald MM, Bokko P, Little DG (2008) Bone remodeling during fracture repair: The cellular picture. Semin Cell Dev Biol 19: 459-466.

5. Szilvassy SJ (2003) The biology of hematopoietic stem cells. Arch Med Res 34: $446-460$

6. Iwakura T, Miwa M, Sakai Y, Niikura T, Lee SY, et al. (2009) Human hypertrophic nonunion tissue contains mesenchymal progenitor cells with multilineage capacity in vitro. J Orthop Res 27: 208-215.

7. Barry FP (2003) Mesenchymal stem cell therapy in joint disease. Novartis Found Symp 249: 86-96.

8. Buckwalter JA, Mankin HJ (1998) Articular cartilage: degeneration and osteoarthritis, repair, regeneration, and transplantation. Instr Course Lect 47 487-504.

9. Caplan Al (1991) Mesenchymal stem cells. J Orthop Res 9: 641-650.

10. Carter DR, Beaupre GS, Giori NJ, Helms JA (1998) Mechanobiology of skeletal regeneration. Clin Orthop Relat Res : S41-55.

11. Johnstone B, Yoo JU (1999) Autologous mesenchymal progenitor cells in articular cartilage repair. Clin Orthop Relat Res S156-162.

12. Luyten FP (2004) Mesenchymal stem cells in osteoarthritis. Curr Opin Rheumatol 16: 599-603.

13. Magne D, Vinatier C, Julien M, Weiss P, Guicheux J (2005) Mesenchymal stem cell therapy to rebuild cartilage. Trends Mol Med 11: 519-526.

14. Murphy JM, Fink DJ, Hunziker EB, Barry FP (2003) Stem cell therapy in a caprine model of osteoarthritis. Arthritis Rheum 48: 3464-3474.

15. Nevo Z, Robinson D, Horowitz S, Hasharoni A, Yayon A (1998) The manipulated mesenchymal stem cells in regenerated skeletal tissues. Cell Transplant 7: 6370 .

16. Noël D, Djouad F, Jorgense C (2002) Regenerative medicine through mesenchymal stem cells for bone and cartilage repair. Curr Opin Investig Drugs 3: 1000-1004.

17. Redman SN, Oldfield SF, Archer CW (2005) Current strategies for articular cartilage repair. Eur Cell Mater 9: 23-32.

18. Tallheden T, Dennis JE, Lennon DP, Sjögren-Jansson E, Caplan Al, et al (2003) Phenotypic plasticity of human articular chondrocytes. J Bone Joint Surg Am 85-85A Suppl 2: 93-100.

19. Wakitani S, Goto T, Pineda SJ, Young RG, Mansour JM, et al. (1994) Mesenchymal cell-based repair of large, full-thickness defects of articular cartilage. J Bone Joint Surg Am 76: 579-592.

20. Walsh CJ, Goodman D, Caplan AI, Goldberg VM (1999) Meniscus regeneration in a rabbit partial meniscectomy model. Tissue Eng 5: 327-337.

21. Muschler GF, Nitto H, Matsukura Y, Boehm C, Valdevit A, et al. (2003) Spine fusion using cell matrix composites enriched in bone marrow-derived cells. Clin Orthop Relat Res: 102-118.

22. Kim SJ, Shin YW, Yang KH, Kim SB, Yoo MJ, et al. (2009) A multi-center randomized, clinical study to compare the effect and safety of autologous cultured osteoblast (Ossron) injection to treat fractures. BMC Musculoskelet Disord 10: 20

23. Centeno CJ, Busse D, Kisiday J, Keohan C, Freeman M, et al. (2008) Regeneration of meniscus cartilage in a knee treated with percutaneously implanted autologous mesenchymal stem cells. Med Hypotheses 71: 900-908.

24. Centeno CJ, Busse D, Kisiday J, Keohan C, Freeman M, et al. (2008) Increased knee cartilage volume in degenerative joint disease using percutaneously implanted, autologous mesenchymal stem cells. Pain Physician 11: 343-353.

25. Centeno CJ, Schultz JR, Cheever M, Robinson B, Freeman M, et al. (2010) Safety and complications reporting on the re-implantation of culture-expanded mesenchymal stem cells using autologous platelet lysate technique. Curr Stem Cell Res Ther 5: 81-93.

26. Bhargava A, Vagela M, Lennox CM (2009) "Challenges in the management of fractures in osteopetrosis"! Review of literature and technical tips learned from long-term management of seven patients. Injury 40: 1167-1171.

27. Birnbaum K, Wirtz DC, Siebert CH, Heller KD (2002) Use of extracorporeal shock-wave therapy (ESWT) in the treatment of non-unions. A review of the literature. Arch Orthop Trauma Surg 122: 324-330.

28. Bochlogyros PN (1985) Non-union of fractures of the mandible. J Maxillofac Surg 13: 189-193.

29. EL-ZORKANI MK (1959) The treatment of non-union of fractures of the long bones: a review of fifty one cases. J Egypt Med Assoc 42: 361-369. 
Citation: Centeno CJ, Schultz JR, Cheever M, Freeman M, Robinson B (2011) A Case Series of Percutaneous Treatment of Non-Union Fractures with Autologous, Culture Expanded, Bone Marrow Derived, Mesenchymal Stem Cells and Platelet Lysate. J Bioengineer \& Biomedical Sci S2:007. doi:10.4172/2155-9538.S2-007

30. Taylor D, Hazenberg J, Lee TC (2006) The cellular transducer in bone: What is it? Technol Health Care 14: 367-377.

31. Bielby R, Jones E, McGonagl D (2007) The role of mesenchymal stem cells in maintenance and repair of bone. Injury, 38: S26-32.

32. D'Ippolito G, Schiller PC, Ricordi C, Roos BA, Howard GA (1999) Age-related osteogenic potential of mesenchymal stromal stem cells from human vertebral bone marrow. J Bone Miner Res 14: 1115-1122.

33. Jones LC, Hungerford DS (2007) The pathogenesis of osteonecrosis. Instr Course Lect 56: 179-196.

34. Muschler GF, Nitto H, Boehm CA, Easley KA (2001) Age- and gender-related changes in the cellularity of human bone marrow and the prevalence of osteoblastic progenitors. J Orthop Res 19: 117-125.

35. Wang Z, Goh J, Das De S, Ge Z, Ouyang H, et al. (2006) Efficacy of bone marrow-derived stem cells in strengthening osteoporotic bone in a rabbit model. Tissue Eng 12: 1753-1761.

36. Koga H, Shimaya M, Muneta T, Nimura A, Morito T, et al. (2008) Local adherent technique for transplanting mesenchymal stem cells as a potential treatment of cartilage defect. Arthritis Res Ther 10: R84.

37. Walker DH, Wright NM (2002) Bone morphogenetic proteins and spinal fusion Neurosurg Focus 13: e3.

38. Wong DA, Kumar A, Jatana S, Ghiselli G, Wong K (2008) Neurologic impairment from ectopic bone in the lumbar canal: a potential complication of off-label PLIF/ TLIF use of bone morphogenetic protein-2 (BMP-2). Spine J 8: 1011-1018.
39. Coronel MF, Musolino PL, Villar MJ (2006) Selective migration and engraftment of bone marrow mesenchymal stem cells in rat lumbar dorsal root ganglia after sciatic nerve constriction. Neurosci Lett 405: 5-9.

40. Crigler L, Robey RC, Asawachaicharn A, Gaupp D, Phinney DG (2006) Human mesenchymal stem cell subpopulations express a variety of neuro-regulatory molecules and promote neuronal cell survival and neuritogenesis. Exp Neurol 198: 54-64.

41. Scuteri A, Cassetti A, Tredici G (2006) Adult mesenchymal stem cells rescue dorsal root ganglia neurons from dying. Brain Res 1116: 75-81.

42. Scuteri A, Donzelli E, Ravasi M, Tredici G (2008) Adult mesenchzymal stem cells support cisplatin-treated dorsal root ganglion survival. Neurosci Lett 445 68-72.

43. Pitton MB, Herber S, Koch U, Oberholzer K, Drees P, et al. (2008) CT-guided vertebroplasty: analysis of technical results, extraosseous cement leakages and complications in 500 procedures. Eur Radiol 18: 2568-2578.

44. Griffin XL, Smith CM, Costa ML (2009) The clinical use of platelet-rich plasma in the promotion of bone healing: a systematic review. Injury 40: 158-162.

45. Simman R, Hoffmann A, Bohinc RJ, Peterson WC, Russ AJ (2008) Role of platelet-rich plasma in acceleration of bone fracture healing. Ann Plast Surg 61: 337-344.

46. Mehta S, Watson JT (2008) Platelet rich concentrate: basic science and current clinical applications. J Orthop Trauma 22: 432-438. 